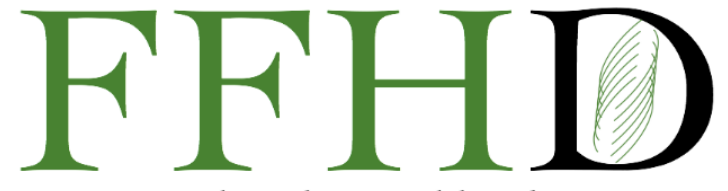

Functional Foods in Health and Disease

\title{
Choosing Suitable Food Vehicles for Functional Food Products
}

\author{
Gloria Aderonke Otunola ${ }^{1 *},{ }^{2}$ Danik Martiryosan
}

${ }^{1}$ Medicinal Plants and Economic Development (MPED) Research Center, Department of Botany, University of Fort Hare, Alice 5700, South Africa.; ${ }^{2}$ Functional Food Center/Functional Food Institute, 7575 Frankford Rd, Suite 3527, Dallas, TX 75252, USA

*Corresponding author: Gloria Aderonke Otunola. Medicinal Plants and Economic Development (MPED) Research Center, Department of Botany, University of Fort Hare, Alice 5700, South Africa Otunola

Submission Date: December $9^{\text {th }}, 2020$; Acceptance Date: January $27^{\text {th }}, 2021$ Publication Date: February $16^{\text {th }}$, 2021

Please cite this article as: Otunola G.A., Martirosyan D. Choosing suitable food vehicles for functional food products. Functional Foods in Health and Disease 2021. 11(2): 44-55. DOI: https://www.doi.org/10.31989/ffhd.v11i2.764

\section{ABSTRACT}

Globally, there is a growing demand for functional foods that provide health benefits without changing current dietary habits. However, the world is made up of diverse societies that consist of a wide range of individuals from different ethnic and cultural backgrounds associated with different food choices and preferences. Functional foods resemble traditional foods but have been designed and tailored to confer physiological and health benefits that go beyond their nutritional function. Of the seven-step cycle involved in functional food

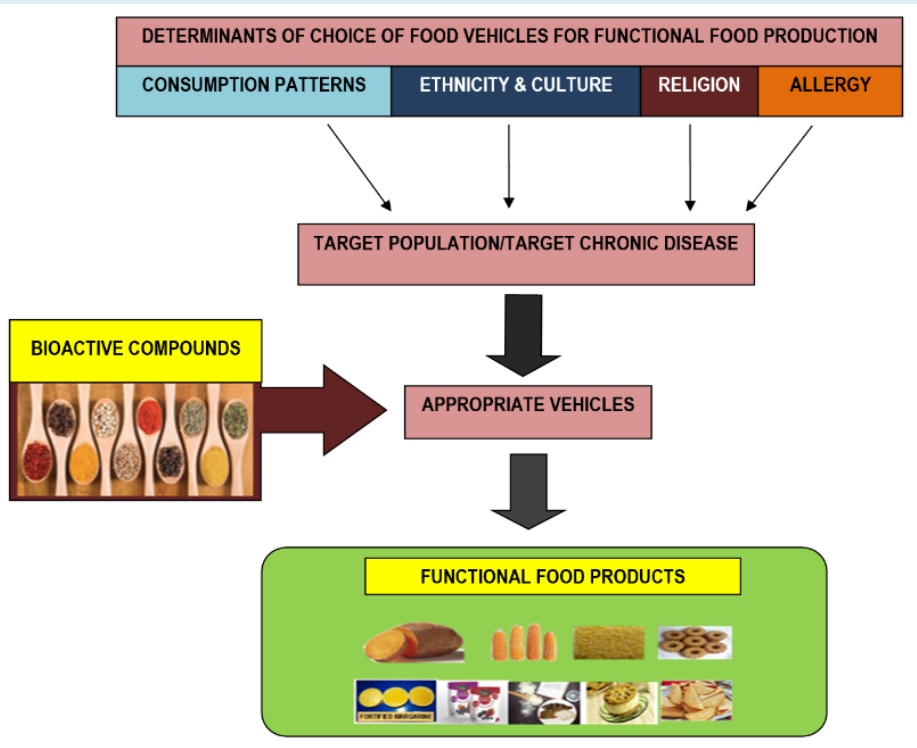
production, choosing a suitable food vehicle as a carrier of the bioactive components is essential. Therefore, this review explored the importance of food vehicles and how they can influence the acceptance of functional foods. Relevant scientific literature was electronically sourced from Google Scholar, Google, PubMed, databases of the Journals of Functional Foods in Health and Disease (JFFHD) and Bioactive Compounds in Health and Disease (BCHD) based on their mention or discussion of food choice and preference and food vehicles for food fortification or functional food production. These studies revealed that although functional foods are found virtually in all food categories, they are not homogeneously scattered over all segments of the growing market. Consumer demands and acceptance in terms of consumption patterns, ethnicity, culture, 
religion, and allergy, amongst others, need to be taken into consideration when choosing appropriate vehicles for functional food development.

Keywords: food vehicles, functional foods, food fortification, food choice, food preference, fortification, phytonutrients, bioactive compounds

CFFC 2021. This is an Open Access article distributed under the terms of the Creative Commons Attribution 4.0 License (http://creativecommons.org/licenses/by/4.0)

\section{INTRODUCTION}

Functional foods are natural or processed foods that contain known or unknown biologically-active compounds, which, in defined, effective, and nontoxic amounts, provide a clinically proven and documented health benefit for the prevention, management, or treatment of chronic diseases [1]. Globally, there is a growing demand for functional foods that provide health benefits without changing current dietary habits. However, the world is made up of diverse societies that consist of a wide range of individuals from different ethnic and cultural backgrounds. According to [2], ethnicity refers to a group of people who share certain distinctive features, such as language, culture, physical appearance, religion, values, and customs; culture is how things are viewed and done among a specific group or population. For society to function efficiently and smoothly, these individuals must learn to integrate and coexist together. They may even adjust their diets because culture and ethnicity have a huge impact on diet, which results in health changes. Therefore, the choices and selections of food that people make, and the classes of foods they eat, will vary widely. This will also directly or indirectly affect the choices of appropriate vehicles for functional food products. The main purpose of this review is to explore the importance of food vehicles and how they can influence the acceptance of functional foods.

\section{METHODS}

The manuscript is a review article. Recent studies, reviews, and relevant literature were retrieved from Google Scholar, Google, and PubMed search engines based on their mention or discussion on the choice of food vehicles for food fortification or functional food production. The databases of the
Journals of Functional Foods in Health and Disease (FFHD) and Bioactive Compounds in Health and Disease (BCHD) were also searched for relevant studies on food vehicles. The keywords/search terms used include food vehicles, functional foods, food fortification, food choice, food preference, ethnicity, culture, religion, fortification, phytonutrients, and bioactive compounds. Noncommunicable diseases (NCDs) such as heart disease, stroke, cancer, chronic respiratory diseases, obesity and diabetes are the most common causes of premature death and morbidity around the world. NCDs also have a huge impact on health-care costs, productivity, and growth [3-4]. The term chronic is often applied when the course of a disease lasts for more than three months [5] and the main types of chronic diseases are cardiovascular diseases, cancers, chronic respiratory diseases (e.g., chronic obstructive pulmonary disease and asthma) and diabetes [4-6]. Others include obesity, osteoporosis, epilepsy, Alzheimer's disease, hyperlipidemia, and inflammatory bowel disease. Chronic diseases generally cannot be prevented by vaccines or cured by medication, nor do they just disappear, but they are largely preventable if interventions are targeted at risk factors and determinants. Thus, the approach for dealing with chronic diseases must go beyond medical treatment for those who are already affected. Diet has been known for many years as a risk factor for chronic diseases and nutritional therapy has become a healing system using dietary therapeutics. Nutritional therapy mainly uses functional food, nutraceuticals, and dietary supplements to promote natural healing. 
Phytonutrients in the treatment of chronic diseases: Phytonutrients (bioactive compounds) are derived from plants and have health-promoting properties [7]. Besides the major nutrients such as carbohydrates and proteins, plants contain phytonutrients, also referred to as bioactive compounds, which have biological activity against chronic diseases [8]. Some of the important bioactive phytonutrients include:

1. Polyphenols e.g., phenols, flavonoids, tannins, coumarins, lignans, gallic acid, anthocyanins, quercetin, resveratrol.

2. Alkaloids e.g., caffeine

3. Organ Sulphur compounds e.g., allicin, isothiocyanates, indoles.

4. Carotenoids e.g., alpha \& beta carotene, lutein, lycopene, astaxanthin, zeaxanthin.

5. Phytosterols e.g., campesterol, sistosteros, stigmastanol, stigmasterol, sistostanol.

6. Nitrogen-containing compounds e.g. betaines, pyridine, piperidine, quinoline.

These phytonutrients exert specific pharmacological effects such as anti-microbial, antioxidants, anti-inflammatory, anti-allergic, antispasmodic, anti-cancer, anti-aging, hepatoprotective, hypolipidemic, neuroprotective, hypotensive, anti-diabetes, anti-obesity, and antiosteoporosis. Many also act as CNS stimulants, analgesics, give protection from UV-induced carcinogenesis, immuno-modulators, and carminatives on human health [9]. Generally, these phytonutrients are obtained from fruits, vegetables, herbs, medicinal plants, and spices.

Production of Functional Foods: Functional foods resemble traditional foods but have been designed and tailored to confer physiological and health benefits that go beyond their nutritional function. According to [10] functional foods must be made available to consumers in forms that are consumed within the usual daily dietary pattern of the target population group because consumers expect functional foods to have good organoleptic qualities (e.g., good aroma, taste, texture, and visual aspects) and to be of similar qualities to the traditional foods in the market. Functional food development involves several distinct stages from concept to successful market implementation. Although functional foods are found virtually in all food categories, they are not homogeneously scattered over all segments of the growing market. Several authors posit that the development and commerce of functional food products are complex, expensive, and risky since potential technological obstacles, legislative aspects, and consumer demands, and acceptance must be taken into consideration when developing functional foods [11-15]. The FFC agrees with the IFT that bringing functional foods to the mass market requires a series of steps involving research, communication with government agencies, and effective public marketing $[1,16]$. However, the FFC has created a seven-step cycle of functional food production. The first step includes the link between a particular food and health benefits. In step 2, in vitro and in vivo studies with non-living and animal specimens, respectively, are conducted, followed by human studies in step 3 (administering human-appropriate dosages of bioactive compounds and testing for adverse side effects or toxicity). Development of appropriate food vehicles for the bioactive compounds follows in step 4, and step 5 consists of marketing to the public and educating them about the health benefits of functional foods. In step 6 , epidemiological studies that involve the assessment of populations to test for long-term effects and overall product effectiveness are conducted. Finally, in step 7, public attitudes toward functional food are measured [1]. Figure 1 shows the major steps involved in the production of functional foods. 


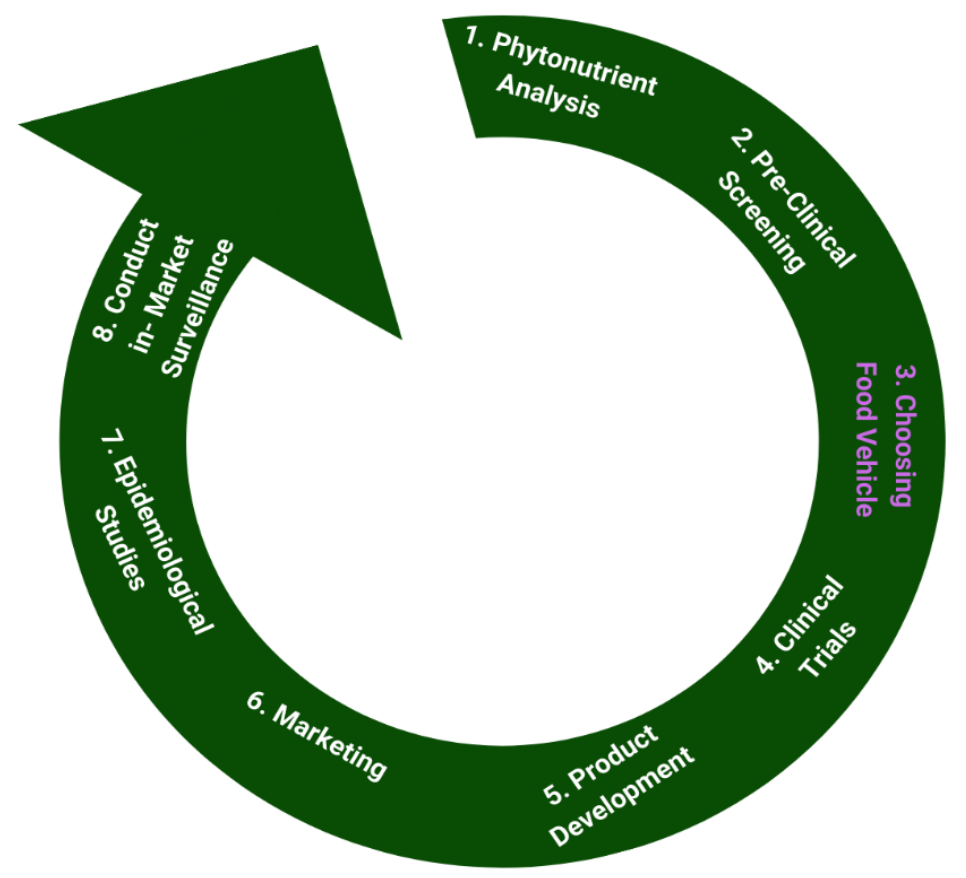

Figure 1. Steps involved in functional food product development and bringing them to the market

Of these seven steps involved in the production of functional foods, the fourth step, product development, is majorly dependent on choosing an appropriate and suitable vehicle to carry the bioactive components. Incorporating active ingredients into appropriate food matrices is a challenging aspect in the development of functional food products because the final product must resemble and taste like the natural food and must be stable. Therefore, in choosing a vehicle for the production of functional foods, a lot of factors come into play, as will be discussed.

Choosing a vehicle: In the development of functional foods, it is often necessary to fortify everyday natural or processed food staples, snacks, or beverages with bioactive compounds or phytonutrients. One of the key processes in developing a functional food product is a suitable food vehicle. This can be challenging, especially in countries with large rural populations, multiple cultures, ethnicities, and religions, as well as globally across countries and regions, as these are all factors in diet diversity.

1. The selection of a food vehicle depends on the acceptability, stability, and bioavailability of the bioactive ingredients within the food, as well as the consumption and lifestyle practices of the intended population. A good vehicle for functional food products should have the following characteristics: The selected food vehicle should be consumed by a large section of the population at the level necessary to achieve the benefit, but not at levels so great as to be toxic.

2. The vehicle should contain the amounts of the phytonutrients necessary to impart desired physiological actions. The phytonutrient content should neither be in excess or insufficiency and should take into account intake from other dietary sources.

3. The vehicle should be such that it will target specific chronic diseases.

4. The food should be stable under conditions of packaging, storage, distribution, and usage.

5. The phytonutrients should be easily available from the food vehicle.

6. Fortification should not impart undesirable taste, color, aroma, or texture to the food.

7. The cost of the fortified food should be reasonable for consumers.

To identify a good food vehicle, data are needed on food production, consumption patterns, imports and exports, prevalent chronic diseases, ethnicities, cultures, religions, geographical locations, and genders of the population, amongst others.

Consumption patterns: Food consumption data of individuals are needed for adequate assessment of the nutritional value of the food supply, assessment of the intake of incidental contaminants, currently approved and possible new food additives, and for 
development of food fortification policies and nutritional quality standards for food products $[17,18]$. Knowledge of consumption patterns is necessary to identify an appropriate vehicle for fortification. Unless the food is eaten in predictable amounts regularly by the target population, the product may not be effective. Knowledge of consumption levels is also needed to determine how much phytonutrient(s) can be safely added to the food vehicle. Several studies have reported differences in consumption patterns across regions, countries, urban and rural communities, and worldwide [19-21]. Differences in foods consumed by urban versus rural populations exist even within the same countries and regions and must be considered before choosing a fortification vehicle. For instance, food consumption patterns in the US differ greatly from those in Asian or African communities; these patterns also differ intra- and inter- continentally. Worldwide, consumption patterns of certain foods such as wheat, corn, oil, sugar, yogurt, and certain beverages (tea, coffee, cocoa), however, indicate that these foods are potentially good vehicles for fortification globally. Tables 1 and 2 show the global and regional per capita food consumption and of livestock products projected to 2030 .

Table 1. Global and regional per capita food consumption (kcal per capita per day)

\begin{tabular}{|c|c|c|c|c|c|c|}
\hline \multirow[t]{2}{*}{ Region } & \multicolumn{5}{|c|}{ kcal per capita per day } & \multirow[b]{2}{*}{2030} \\
\hline & 1964-1966 & 1974-1976 & 1984-1986 & 1997-1999 & 2015 & \\
\hline World & 2358 & 2435 & 2655 & 2803 & 2940 & 3050 \\
\hline Developing countries & 2054 & 2152 & 2450 & 2681 & 2850 & 2980 \\
\hline Near East and North Africa & 2290 & 2591 & 2953 & 3006 & 3090 & 3170 \\
\hline Sub-Saharan Africa & 2058 & 2079 & 2057 & 2195 & 2360 & 2540 \\
\hline $\begin{array}{l}\text { Latin America and the } \\
\text { Caribbean }\end{array}$ & 2393 & 2546 & 2689 & 2824 & 2980 & 3140 \\
\hline East Asia & 1957 & 2105 & 2559 & 2921 & 3060 & 3190 \\
\hline South Asia & 2017 & 1986 & 2205 & 2403 & 2700 & 2900 \\
\hline Industrialized countries & 2947 & 3065 & 3206 & 3380 & 3440 & 3500 \\
\hline Transition countries & 3222 & 3385 & 3379 & 2906 & 3060 & 3180 \\
\hline
\end{tabular}

Table 2. Global and regional per capita consumption of meat and milk products

\begin{tabular}{|c|c|c|c|c|c|c|}
\hline \multirow{3}{*}{$\begin{array}{l}\text { Region } \\
\text { World }\end{array}$} & \multicolumn{3}{|c|}{ Meat (kg per year) } & \multicolumn{3}{|c|}{ Milk (kg per year) } \\
\hline & 1964-1966 & 1997-1999 & \multirow{2}{*}{$\begin{array}{l}2030 \\
45.3\end{array}$} & $1964-1966$ & 1997-1999 & \multirow{2}{*}{$\begin{array}{r}2030 \\
89.5\end{array}$} \\
\hline & 24.2 & 36.4 & & 73.9 & 78.1 & \\
\hline Developing countries & 10.2 & 25.5 & 36.7 & 28.0 & 44.6 & 65.8 \\
\hline Near East and North Africa & 11.9 & 21.2 & 35.0 & 68.6 & 72.3 & 89.9 \\
\hline Sub-Saharan Africa & 9.9 & 9.4 & 13.4 & 28.5 & 29.1 & 33.8 \\
\hline $\begin{array}{l}\text { Latin America and the } \\
\text { Caribbean }\end{array}$ & 31.7 & 53.8 & 76.6 & 80.1 & 110.2 & 139.8 \\
\hline East Asia & 8.7 & 37.7 & 58.5 & 3.6 & 10.0 & 17.8 \\
\hline South Asia & 3.9 & 5.3 & 11.7 & 37.0 & 67.5 & 106.9 \\
\hline Industrialized countries & 61.5 & 88.2 & 100.1 & 185.5 & 212.2 & 221.0 \\
\hline Transition countries & 42.5 & 46.2 & 60.7 & 156.6 & 159.1 & 178.7 \\
\hline
\end{tabular}


Ethnicity and cultural factors: The ethnicity of the target population is another factor that should be considered when choosing food vehicles for functional foods. Individual ethnic groups have different preferences for different foods because people who belong to the same ethnic groups have been raised and brought up in a certain style and manner, which affects their outlook and attitudes towards life, people, health and even food instilled into individuals of these groups at an early age [2]. For example, African and Afro Caribbean groups will usually consume foods that contain different types of meat, grains, tubers, and roots; Eastern and far eastern groups will lean towards foods rich in various herbs and spices, while Western groups will consume foods that are much dryer and plainer, but with higher meat content than other ethnic groups.

Several studies have reported the influence of ethnicity and culture on dietary patterns and food choices that could inadvertently affect the acceptability of functional foods [22-24]. For instance, a study reported that Malay adolescents had significantly higher scores for the Westernbased food pattern and local-based food pattern, whereas Chinese adolescents showed higher scores for the healthy-based food pattern [22]. Culturally, foods frowned upon by some cultures may be encouraged by others, while some foods forbidden to some cultures could be the delicacy of others. In addition, some cultures frown upon or encourage the consumption of certain foods at different stages of life due to the benefits or dangers of consuming these foods at those stages. Some of these foods include alcohol, certain meats and parts of meat, mushrooms, vegetables, beverages, fruits, and vegetables [2].

An association between ethnicity and dietary patterns was reported by Rashid et al. [23]; these include snacking patterns being related to white ethnicity at age 3 and 7, a healthy pattern with nonwhite ethnicity at age 4 to 7 years, but both higher healthy and snacking pattern scores in non-Dutch groups. Previous studies have also reported higher consumption of fruit and vegetables in 7-9-year-old children of Turkish and Moroccan origin and 9-10year-old children from the non-western origin than that of Dutch children in the Netherlands [25-26]. Also, Surinamese children were reported to have higher meat pattern scores than children from other ethnic groups and Turkish children have higher full-fat pattern scores [27]. Particular eating habits related to ethnic and cultural factors must be considered when choosing vehicles for functional food development. It follows that, since the development of "functional foods" is aimed at being consumed within the habitual diet, the prevalent ethnic or cultural food matrix should be chosen as vehicles. For instance, considering the present state of trends in meat consumption, meat can be a very suitable and appropriate vehicle for functional foods tailored for chronic diseases among ethnic and cultural groups who consume a lot of meats.

Several studies have reported the development of functional foods using vehicles based on the prevalent food choices or preferences of ethnic groups [24, 28-31]. Considering that meat and meat products are essential components of diets in most countries and the evidence that relate them to an increased risk for CVD, [32] developed meat-based functional food products with nuts (walnuts). These authors reported that regular consumption of walnut-enriched meat products compared with that of the restructured meat products without added walnuts provoked a decrease in total cholesterol of $6.8 \mathrm{mg} / \mathrm{dl}$. Compared to baseline (mixed diet), meat products with walnuts decreased total cholesterol $(-10.7$ $\mathrm{mg} / \mathrm{dl}, \mathrm{Cl}(95 \%):-17.1,-4.2)$, LDL cholesterol (-7.6 $\mathrm{mg} / \mathrm{dl}, \mathrm{Cl}(95 \%):-2.2,-13.0)$ and body weight (-0.5 $\mathrm{kg}, \mathrm{Cl}(95 \%):-0.1,-0.9)$ and increased gammatocopherol (8.9 mg/dl, Cl(95\%): 1.0, 16.8).

In cultures where dairy products are the prevalent food choices, these should be used as vehicles for the production of functional foods. Guzel-Seydim et al. [33] reported the effects of fermented dairy products against cancer, pathogens, and other health issues in traditional, ethnic communities. The authors reported that plain set type yogurt is considered important for healthy nutrition in Turkey, so much so that it is a significant food for babies from 6-months old. Keffir, a complex fermented dairy product that was first consumed among the people of the Northern Caucasian mountains located in the Eurasian region between the Caspian and Black seas, has become 
particularly important in Russian nutrition and is even recommended at hospitals, sanatoriums, and is reportedly mandatory to ensure workers' good health and mood; its use has spread through Eastern Europe and into Asia [34-36]. Koumiss, Dahi and Yakult are three different fermented dairy products with functional properties common to the Chinese, Indian, and Japanese, respectively, with a reported positive impact on health and cancer [33, 37-40]. Table 2 shows some functional foods from dairy products that are specific to certain ethnic and cultural groups.

Again, some cultures relegate foods on a gender basis. For instance, in African settings, men seem to have a right over meat because it is assumed that meat gives men more strength (especially sexual strength); while the meat is considered masculine and fit for men, fish is considered as unfit because it is 'feminine.' Even among the French working class, fish is considered an inappropriate food for men because it is light, insubstantial, and 'fiddly' to eat [41-42]. In another context, sometimes the gender to which the food is associated might not be allowed to eat that type of food, because eating that type of food is tantamount to self-destruction, (e.g., women do not eat lungfish in some parts of Uganda because it has breasts; in some parts of Africa, women are not allowed to eat antelope or crocodile meat for fear that they will be jumpy and aggressive, respectively). In some parts of South Africa, young girls are not allowed to eat eggs, avocado, peanuts and fresh milk for fear that they would become sexually active at an early age, while Xhosa men were not allowed to eat vegetables besides cabbages and spinach for fear that they would become sexually weak $[42,43]$.

Religion: Religion plays one of the most influential roles in the choices and subsequent selection of foods consumed in certain societies. Just like culture, religion also shapes the food choices and preferences in communities. However, culture is dynamic, but religion is more rigid and often unchangeable as some religions affect the consumption of food and what to eat at certain times, and frowns at violating religious edicts on foods $[42,44-45]$.
For example, in the Hindu and Buddhist religions, the consumption of both pork and beef is frowned upon because they are considered unclean meat; the consumption of pork and not beef is prohibited for the same reasons in the Islamic religion and Judaism, but all other meats consumed in these religions must be halal and kosher, respectively, i.e., special prayers must be said to make the eating of these animals acceptable [2]. In contrast, Christianity and the Catholic religion allow the consumption of any types of meat without the need for any kind of repentance to God, while at the other extreme, the Jain religion does not allow the eating of any meat, nor does it allow consumptions of vegetables grown beneath the soil [2]. Buddhism supports vegetarianism, in respect for animals, considered before all as living beings, though some include fish in their diet, while Hinduism prohibits onions, garlic, and red-colored foods such as red lentils and tomatoes.

In another instance, the use of wine in religious ceremonies is acceptable by certain groups. For example, Roman Catholics, Eastern Orthodox Christians, and certain Protestant denominations use wine as a sacramental product to represent the blood of Christ in communion services. Mormons, however, specifically forbid wine or any alcoholic drinks because of their stimulant properties, while Jews regard grapes as a fruit of idolatry and therefore forbid the use of wine or products made from grapes except under special conditions $[42,46]$.

In another context in Ethiopia, according to D'Haene et al. [47] "rules and restrictions are inherent to religious institutions and often relate to dietary practices, which give rise to distinct consumption patterns and are established either temporarily (such as fasting) and/or permanently (e.g., restriction to kosher and halal food in Jewish and Islamic traditions, respectively), require either abstinence from all (e.g., Ramadan from dawn to sunset) or certain foods (e.g., by the abstinence from animal source foods for Orthodox Christians)." These restrictions could therefore prevent the acceptability of functional foods, where religion forbids the vehicle. For instance, Ethiopia hosts the largest estimated livestock herd in sub-Saharan Africa, yet Ethiopian diets contain relatively little 
animal source foods, especially milk $[47,48]$. Table

3 shows food restrictions according to religion. The importance of certain dietary practices in these religions is evident.

Table 3. Religious Food Restrictions

\begin{tabular}{|c|c|c|}
\hline Religion & Food Restriction & Reason \\
\hline Buddhism & $\begin{array}{l}\text { Refrain from meat, a vegetarian diet is } \\
\text { desirable, Moderation in all foods, Fasting required } \\
\text { of monks }\end{array}$ & $\begin{array}{l}\text { Natural foods of the earth are considered most } \\
\text { pure, Monks avoid all solid food after noon }\end{array}$ \\
\hline $\begin{array}{l}\text { Eastern } \\
\text { Orthodox } \\
\text { Christianity }\end{array}$ & Restrictions on meat and fish, fasting selectively & $\begin{array}{l}\text { Observance of Holy days includes fasting and } \\
\text { restrictions to increase spiritual progress }\end{array}$ \\
\hline Hinduism & $\begin{array}{l}\text { Beef prohibited, All other meat and fish restricted } \\
\text { or avoided, Alcohol avoided, Numerous fasting days }\end{array}$ & $\begin{array}{l}\text { The ow is sacred and cannot be eaten, but } \\
\text { products of the "sacred" cow are pure and } \\
\text { desirable; Fasting promotes spiritual growth }\end{array}$ \\
\hline Islam & $\begin{array}{l}\text { Pork and certain birds prohibited, Alcohol } \\
\text { prohibited, Coffee/tea/stimulants avoided, Fasting } \\
\text { from all food and drink during specific periods }\end{array}$ & $\begin{array}{l}\text { Eating is for good health, Failure to eat correctly } \\
\text { minimizes spiritual awareness, Fasting has a } \\
\text { cleansing effect of evil elements }\end{array}$ \\
\hline Judaism & $\begin{array}{l}\text { Pork and shellfish prohibited, Meat and dairy at } \\
\text { same meal prohibited, Leavened food restricted, } \\
\text { Fasting practiced }\end{array}$ & $\begin{array}{l}\text { Land animals that do not have cloven hooves } \\
\text { and that do not chew their cud are forbidden as } \\
\text { unclean (e.g., hare, pig, camel), Kosher process is } \\
\text { based upon the Torah }\end{array}$ \\
\hline Mormonism & $\begin{array}{l}\text { Alcohol and beverages containing caffeine } \\
\text { prohibited, Moderation in all foods, Fasting } \\
\text { practiced }\end{array}$ & $\begin{array}{l}\text { Caffeine is addictive and leads to poor physical } \\
\text { and emotional health, Fasting is the discipline of } \\
\text { self-control and honoring to God }\end{array}$ \\
\hline Protestants & $\begin{array}{l}\text { Few restrictions of food or fasting observations, } \\
\text { Moderation in eating, drinking, and exercise is } \\
\text { promoted }\end{array}$ & $\begin{array}{l}\text { God made all animal and natural products for } \\
\text { human enjoyment, Gluttony and drunkenness } \\
\text { are sins to be controlled }\end{array}$ \\
\hline Rastafarianism & $\begin{array}{l}\text { Meat and fish restricted, Vegetarian diets only, with } \\
\text { salts, preservatives, and condiments prohibited, } \\
\text { Herbal drinks permitted; alcohol, coffee, and soft } \\
\text { drinks prohibited, Marijuana used extensively for } \\
\text { religious and medicinal purposes }\end{array}$ & $\begin{array}{l}\text { Pigs and shellfish are scavengers and are } \\
\text { unclean, Foods grown with chemicals are } \\
\text { unnatural and prohibited, Biblical texts support } \\
\text { use of herbs (marijuana and other herbs) }\end{array}$ \\
\hline $\begin{array}{l}\text { Roman } \\
\text { Catholicism }\end{array}$ & Meat restricted on certain days, Fasting practiced & $\begin{array}{l}\text { Restrictions are consistent with specified days of } \\
\text { the church year }\end{array}$ \\
\hline $\begin{array}{l}\text { Seventh-day } \\
\text { Adventist }\end{array}$ & $\begin{array}{l}\text { Pork prohibited and meat and fish avoided, } \\
\text { Vegetarian diet is encouraged }- \text { Alcohol, coffee, } \\
\text { and tea prohibited }\end{array}$ & Diet satisfies practice to "honor and glorify God" \\
\hline
\end{tabular}

Source: https://www.encyclopedia.com/food/news-wires-white-papers-and-books/religion-and-dietary-practices

Within this context, it follows that cooking and eating utensils must be handled carefully. This is because faiths that practice vegetarianism, such as Hinduism or Sikhism, require that utensils used in the preparation, cooking, and serving of foods have not come into contact with meat, fish, or eggs. Similarly, Islam requires that utensils have not come into contact with pork, non-halal meat or alcohol, although separate utensils are not required, as long as they are thoroughly washed after using them for non-halal food [49]. Utensils used for Jewish people should be separate for milk and meat [50].

Therefore, choosing an appropriate and acceptable food vehicle for functional food production needs to take into consideration the religion of the target population to know what foods their religion permits them to eat. On the other hand, Functional Foods Scientists could integrate religion to create target markets for certain products by highlighting the relationship between functional food products and the vulnerable consumers' religion.

Allergy: Food allergy is a pathological, potentially deadly immune reaction triggered by normally innocuous food protein antigens in foods which can be immunoglobulin (Ig)E-mediated or non-lgEmediated [51-53]. IgE-mediated food allergy is a worldwide health problem that affects millions of persons and numerous aspects of a person's life. It should be noted, however, that reactions that do not involve the immune system (e.g., milk intolerance) are not food allergies [53]. Any food can cause allergy but only a few foods, including 
milk, eggs, peanuts, shellfish, wheat, and nuts account for most allergies and in the last few years, and many cases of near-fatal reactions following food ingestion have been reported. Food allergy is becoming an increasing problem worldwide, with an estimated $6-8 \%$ of children affected at some point in their childhood, $20-30 \%$ of the people interviewed consider that they or a family member have an allergy to a food product and around $22 \%$ implement some form of an elimination diet, on the mere possibility that the food may contain an allergen [54]. For example, lactose intolerance, nut oil and nut product allergies are common among the British population [2]. Therefore, care must be taken to choose vehicles and functional food products that do not contain these foods or food products meant for such populations.

Seeds and nuts are also known to cause allergic reactions in some people. In the EU, but not in the US, sesame and mustard seeds are among the most prevalent allergens with data showing that sesame and mustard seed allergies are geographically disproportionate: high in some areas (France and Spain), much lower in others (Germany and the Nordic countries), unknown in Eastern Europe, and sesame seed allergy is not common outside Israel and Europe [54-57]. Several studies have reported allergies to fruit and vegetables which are of two types: pollen-food syndrome (PFS, secondary IgE mediated food allergy) and lipid transfer protein syndrome (LTP, primary lgE mediated food allergy) [58]. Whereas cooked, canned, baked, or microwave fruits and vegetables are allowed with PFS, they have to be completely avoided in the case of LTP allergies [59].

Sommer et al., [60] reports that food allergic consumers are usually deprived of satisfaction and pleasure from foods, experience difficulties in finding safe foods, and have to be careful with what they eat. According to Seth et al.[61] the symptoms of food allergy vary from mild to severe; in extreme cases, it can lead to anaphylaxis, which is a lifethreatening allergic reaction. This is thus, another important factor to consider when choosing vehicles for, or formulating functional foods. Table 4 shows some foods that cause allergic reactions.

Table 4: Some common foods and their allergic reactions

\begin{tabular}{|c|c|}
\hline Food & Allergic reactions \\
\hline $\begin{array}{l}\text { Nuts especially peanuts, walnuts, and } \\
\text { hazelnuts }\end{array}$ & Stuffy nose, wheezing and low blood pressure. \\
\hline Chicken eggs & Diarrhea and abdominal pain \\
\hline $\begin{array}{l}\text { Fruits containing pips (e.g., the small } \\
\text { seeds in apples, pears, quinces), fruits } \\
\text { containing a large "stone" (e.g., } \\
\text { peaches, nectarines, plums) }\end{array}$ & $\begin{array}{l}\text { Stuffy nose, Sinus infections, Nasal and sinus polyps, Asthma, Diarrhea, Gut } \\
\text { inflammation (colitis), Hives }\end{array}$ \\
\hline Seafood e.g., Fish, crustaceans, mollusks & $\begin{array}{l}\text { Anaphylaxis, hives, wheezing, troubled breathing, cramps, diarrhea, nausea or } \\
\text { vomiting }\end{array}$ \\
\hline Vegetables e.g., Celery, carrots & $\begin{array}{l}\text { Stuffy nose, Sinus infections, Nasal and sinus polyps, Asthma, Diarrhea, Gut } \\
\text { inflammation (colitis), Hive }\end{array}$ \\
\hline Cow milk, & Abdominal pain, Bloating, Diarrhea, Gas, Nausea \\
\hline Legumes e.g., soy & $\begin{array}{l}\text { Swelling in the face, throat and/or mouth, rash, difficulty in breathing, Severe } \\
\text { asthma, abdominal pain, nausea and vomiting }\end{array}$ \\
\hline Gluten from wheat & $\begin{array}{l}\text { Celiac disease, non-celiac gluten sensitivity and wheat allergy, Bloating, } \\
\text { Abdominal pain, diarrhea or constipation, Headaches, Fatigue, Joint pain, Skin } \\
\text { rash, depression or anxiety, anemia }\end{array}$ \\
\hline Meat & itching, hives and stomach cramps \\
\hline Seeds e.g., mustard, sesame, lupin & $\begin{array}{l}\text { Bloating, Abdominal pain, diarrhea or constipation, Headaches, Fatigue, Joint } \\
\text { pain, Skin rash, depression or anxiety, anemia }\end{array}$ \\
\hline
\end{tabular}


With milk and egg allergens, children are usually tolerant to baked milk and egg (such as cookies, waffles, muffins, and pancakes) irrespective of the age or population studied, while baked cheese (pizza) has been suggested for baked milk challenges [62-65]. Food allergy presents a significant health burden at either individual or population levels worldwide. Therefore, care should be taken to ensure adequate intake of nutrients when selecting a suitable alternative vehicle, especially when foods like eggs, milk, fruits, vegetables, or wheat flour are the allergens, to ensure that no essential nutrients are left out. Importantly, information on possible allergens should be on functional food labels.

\section{CONCLUSION}

The development and commerce of functional food products are complex, expensive, and risky because potential technological obstacles, legislative aspects, as well as consumer demands, and acceptance need to be taken into consideration when developing functional foods. Incorporating active ingredients into appropriate food matrices is a challenging aspect in the development of functional food products because the final product must be stable, as well as resemble and taste like natural food. This review reveals that in choosing a vehicle for the production of functional foods, a lot of factors including its acceptability, stability, and bioavailability of the bioactive ingredients within the food and the consumption and lifestyle

\section{REFERENCES}

1. Martirosyan DM, and Singh J: A New Definition for Functional Food by FFC: Creating Functional Food Products Using the New Definition: In Martirosyan D (ed) Introduction to Functional Food Science, Chapter 1, 4th edn, Functional Food Center/Functional Food Institute, 7575 Frankford Rd, Suite 3527, Dallas, TX 75252, USA, 2020, 13-26.

2. Dindyal S, and Dindyal S: How Personal Factors, Including Culture And Ethnicity, Affect The Choices And Selection Of Food We Make. Internet Journal of Third World Medicine. 2003, 1(2).

3. Couser WG, Remuzzi G, Mendis S, and Tonelli M: The contribution of chronic kidney disease to the global burden of major non-communicable diseases. Kidney International. 2011, 80(12): 1258-1270.

4. Branca F, Lartey A, Oenema S, Aguayo V, Stordalen GA, Richardson R, Arvelo $M$, and Afshin A: Transforming the practices of the intended population need to be considered. To identify a good food vehicle, information of the target population's attitude to food production, consumption patterns, prevalent chronic diseases, ethnic, cultural, religion, allergies, geographical and gender of the population amongst others must be known.

Acknowledgments: The authors acknowledge the support of the National Research Foundation (NRF) of South Africa. The authors also thank Camila Nadalet and Danik Martirosyan for editing and providing helpful comments in the preparation of this manuscript.

Conflict of Interest: The authors declare no conflict of interest.

Abbreviations: FFC: Functional Food Center; IFT: Institute of Food Technology; JFFHD: Journal of Functional Foods in Health and Disease; BCHDJ: Bioactive Compounds in Health and Disease Journal; NCDs: Non-communicable diseases; CVD: Cardiovascular diseases; LTP: Lipid transfer protein syndrome; PFS: pollen-food syndrome

Authors' Contribution: Both authors contributed to this work. GAO and DM conceptualized and designed the review, prepared, read and reviewed the manuscript.

food system to fight non-communicable diseases. British Medical Journal. 2019, 364:1296

5. Bernell S, and Howard SW: Use Your Words Carefully: What Is a Chronic Disease? Frontiers in

6. Public Health. 2016, 4:159. doi:10.3389/fpubh.2016.00159.

7. World Health Organization: Non-communicable Diseases.

2016: http://www.who.int/topics/noncommunicable di seases/en/

8. Prior RL, and Cao G: Antioxidant phytochemicals in fruits and vegetables: diet and health implications. Horticultural Sciences. 2000, 35:588-92.

9. Craig W, and Beck L: Phytochemicals: health protection effects. Canadian Journal of Dietetic Practice and Research. 1999, 60:78-84.

10. Gupta C, and Prakash D: Phytonutrients as therapeutic agents. Journal of Complementary and Integrative Medicine. 2014, 11(3):151-169. 
11. Sanguansri $L$, and Augustin AM: Microencapsulation in Functional Food Product Development. In Functional Food Product Development (eds F. Shahidi, J. Smith and E.Charter), 2010, https://doi.org/10.1002/9781444323351.ch1

12. Siro IN, Ka'polna E, Ka'polna B, and Lugasi A: Functional food. Product development, marketing and consumer acceptance-A review. Appetite. 2008, 51: 456-467

13. Bogue J, Collins $O$, and Troy AJ: Market analysis and concept development of functional foods. In: Bagchi D, Nair S (eds), Developing New Functional Food and Nutraceutical Products. Chapter 2 Academic Press. 2017, 29-45. ISBN 9780128027806, https://doi.org/10.1016/B978-0-12-802780-6.00002-X.

14. Lagouri V: Introductory Chapter: Functional Foods. 2018: http//doi:10.5772/ intechopen. 82304

15. Varzakas T, Kandylis P, Dimitrellou D, Salamoura C, Zakynthinos G, and Proestos C: Innovative and fortified food: Probiotics, prebiotics, GMOs and superfood. In: Ali E, Naquiah N, Nizar A (eds) In Woodhead Publishing Series in Food Science, Technology and Nutrition, Preparation and Processing of Religious and Cultural Foods, Woodhead Publishing. 2018, 67-129. ISBN 9780081018927 https://doi.org/10.1016/B978-0-08101892-7.00006-7

16. Granato D, Barba FJ, Bursać KD, Lorenzo JM, Cruz, AG, and Putnik P: Functional Foods: Product Development, Technological Trends, Efficacy Testing, and Safety. Annual Review of Food Science and Technology. 2020, 93 (11):118. doi:10.1146/annurev-food-032519-051708.

17. Martirosyan DM, Singh J: A new definition for functional food by FFC: What makes a new definition unique? Functional Foods in Health and Disease. 2015, 5(6):209223

18. National Research Council (US) Committee on Food Consumption Patterns. Assessing Changing Food Consumption Patterns. Washington (DC): National Academies Press (US). 1981, Introduction. https://www.ncbi.nlm.nih.gov/books/NBK 216698/

19. Nguyen PH, Strizich G, Lowe A: Food consumption patterns and associated factors among Vietnamese women of reproductive age. Nutrition Journal. 2013, 12:126 https://doi.org/10.1186/1475-2891-12-126

20. Kosaka S, Suda K, Gunawan B, Raksanagara A, Watanabe $C$, and Umezaki $M$ : Urban-rural difference in the determinants of dietary and energy intake patterns: $A$ case study in West Java, Indonesia. PLoS One. 2018, 13(5):e0197626. doi:10.1371/journal.pone.0197626

21. Al-Jawaldeh A, Taktouk $M$, and Nasreddine L: Food Consumption Patterns and Nutrient Intakes of Children and Adolescents in the Eastern Mediterranean Region: $A$ Call for Policy Action. Nutrients. 2020, 12: 3345.

22. Le TH, Disegna $M$, and Lloyd $T$ : National Food Consumption Patterns:Converging Trends and the Implications for Health. EuroChoice. 2020, https://doi.org/10.1111/1746-692X.12272

23. Abdullah NF, Teo PS, and Foo LH: Ethnic Differences in the Food Intake Patterns and Its Associated Factors of
Adolescents in Kelantan, Malaysia. Nutrients. 2016, 8(9):551.doi:10.3390/nu8090551

24. Rashid V, Engberink MF, van Eijsden M, Nicolaou M, Dekker LH, Verhoeff AP, and Weijs PJM: Ethnicity and socioeconomic status are related to dietary patterns at age 5 in the Amsterdam born children and their development (ABCD) cohort. BMC Public Health. 2018, 18:115

25. Ardekani A, Askari EH, and Mohagheghzadeh A: Memorial functional foods: a new concept from Bavi tribe. Journal of Ethnic Foods. 2020, 7: 9 https://doi.org/10.1186/s42779-020-00046-4

26. Tak NI, Te Velde SJ, and Brug J: Ethnic differences in 1year follow-up effect of the Dutch Schoolgruiten project promoting fruit and vegetable consumption among primary-school children. Public Health Nutrition. 2007,10:1497-507.

27. The National Public Health Compass (RIVM): http://www.nationaalkompas.nl

/gezondheidsdeterminanten/leefstijl/voeding/zijnerverschillen-naar-etniciteit/Accessed January 252016.

28. Dekker LH, Nicolaou M, van Dam RM, de Vries JH, de Boer EJ, Brants HA, Beukers MH, Snijder MB, and Stronks K: Socio-economic status and ethnicity are independently associated with dietary patterns: the HELIUS-dietary patterns study. Food and Nutrition Research. 2015, 59:26317.

29. Martirosyan DM: Functional foods for chronic diseases: D\&A Inc; 2006.

30. Jana S, Shekhawat G: Anethum graveolens: an Indian traditional medicinal herb and spice. Pharmacognosy Review. 2010, 4(8):179.

31. Askari H: Data collection of folk and traditional medicine of Bavi tribe and consolidation of in vitro four selected sample (Pharm.D. thesis), 2012.

32. Fathi $H$, Mohammad Shahi N, Latifi A, Zamani A, and Shaki F: Evaluation of antiemetic effect of metabolic, aesthetic, and aqueous extracts of Citrus aurantium L. on chicken. J Gorgan Univ Med Sci, 2016:18(3):34-39

33. Olmedilla-Alonso B, Granado-Lorencio F, HerreroBarbudo C, Blanco-Navarro I, Blázquez-García S, and Pérez-Sacristán B: Consumption of restructured meat products with added walnuts has a cholesterol-lowering effect in subjects at high cardiovascular risk: a randomised, crossover, placebo-controlled study. Journal of the American College of Nutrition. 2008, 27(2):342-8. doi: $\quad 10.1080 / 07315724.2008 .10719710 . \quad$ PMID: 18689569.

34. Seydim ZB, Greene AK, Seydim AC, and Kök taş T: Effects of Fermented Dairy products against Cancer, Pathogens and other Health Issues. Danik M. Martirosyan, Jin-Rong Zhou, (eds) Functional Foods and Cancer: Functional Foods in Integrative Oncology. 2017, 35-61 Independent Publishing Platform First Edition (September 17, 2017).

35. Otles S, and Cagindi O: Kefir: A probiotic dairy composition, nutritional and therapeutic aspects. Pakistan Journal of Nutrition. 2003, 2:54-59.

36. Gronnevik H, Falstad M, and Narvhus JA: Microbiological and chemical properties of Norwegian kefir during storage. International Dairy Journal. 2011, 21:601-606 
37. Gul O, Mortas M, Atalar I, Dervisoglu M, and Kahyaoglu T: Manufacture and characterization of kefir made from cow and buffalo milk, using kefir grain and starter culture. Journal of Dairy Science. 2015, 98(3):1517-1525 https://doi.org/10.3168/jds.2014-8755

38. Sun $T$, Zhao $S$, Wang $H$, Cai $C$, Chen $Y$, and Zhang $H$ : ACEinhibitory activity and gamma-aminobutyric acid content of fermented skim milks by Lactobacillus helveticus isolated from Xinjiang koumiss in China. European Food Research and Technology. 2008, 228: 607-612.

39. Yi L, Dang $Y, W u$ J, Zhang L, Liu X, and Liu B: Purification and characterization of a novel bacteriocin produced by Lactobacillus crustorum MN047 isolated from koumiss from Xinjiang, China. Journal of Dairy Science. 2016, 99(9):7002-7015.

40. Kaga C, Takagi A, Kano M, Kado S, Kato I, Sakai M, Miyazaki K, Nanno M, Ishikawa F, Ohashi Y, and Toi M: Lactobacillus casei Shirota enhances the preventive efficacy of soy milk in chemically induced breast cancer. Cancer Science. 2013, 104: 1508-1514

41. Mohania D, Kansal VK, Kruzliak P, and Kumar A: Probiotic Dahi containing Lactobacillus acidophilus and Bifidobacterium bifidum modulates the formation of aberrant crypt foci, mucin-depleted foci, and cell proliferation on 1,2-dimethylhydrazine-induced colorectal carcinogenesis in Wistar rats. Rejuvenation Research. 2013, 17:326-333.

42. Lupton D: Food, the body, and the self London: SAGE Publications Ltd. 1998, doi: 10.4135/9781446221761

43. Byarugaba G: The influence of food symbolism on food insecurity in South Africa: how relevant is the Eucharistic celebration? Scriptura. 2017, 116(1): 1-19 http://dx.doi.org/10.7833/116-1-1335

44. Chakona G, and Shackleton C: Food Taboos and Cultural Beliefs Influence Food Choice and Dietary Preferences among Pregnant Women in the Eastern Cape, South Africa. Nutrients. 2019, 11(11):2668. doi:10.3390/nu11112668

45. Monin B, and Szczurek LM: Food and culture. In Adam B. Cohen's (Ed.) Culture reexamined: Broadening our understanding of social and evolutionary influences.. Washington, DC: American Psychological Association. 2014, 155-190 https://doi.org/10.1037/14274-009

46. Shipman D, and Durmus B: The Effect of Culture on Food Consumption; a Case of Special Religious Days in Turkey. Journal of Food Research. 2017, 6(2): 92-99

47. Waibel RA: "Religion and Dietary Practices ." Nutrition and Well-Being A to Z. Encyclopedia.com. 2020, https://www.encyclopedia.com

48. D'Haene E, Desiere S, D'Haese M, Verbeke W, and Schoors K: Religion, Food Choices, and Demand Seasonality: Evidence from the Ethiopian Milk Market. Foods. 2019, 8(5):167 doi:10.3390/foods8050167

49. Tilahun $\mathrm{H}$, and Schmidt E: Spatial Analysis of Livestock Production Patterns in Ethiopia. International Food Policy Research Institute; Washington, DC, USA: Ethiopian Development Research Institute; Addis Ababa, Ethiopian Strategy Support Program II Working Paper. 2012, No. 44.
50. Naqshbandi M: Muslims in Britain. http://guide.muslimsinbritain.org/guide8.html\#8.2

51. Rich TR: Judaism101. Kashrut: Jewish Dietary Laws. www.jewfaq.org/kashrut.htm\#Shechitah

52. Yu W, Freeland DMH, and Nadeau KC: Food allergy: immune mechanisms, diagnosis and immunotherapy. Natural Review of Immunology. 2016,16(12):751-765. doi:10.1038/nri.2016.111

53. Mazzocchi A, Venter C, Maslin K, and Agostoni C: The Role of Nutritional Aspects in Food Allergy: Prevention and $\begin{array}{ll}\text { Management. Nutrients. 2017, 9(8):850 } & \end{array}$ doi:10.3390/nu9080850

54. Lopez CM, Yarrarapu SNS, Mendez MD: Food Allergies. [Updated 2020 Oct 2]. In: StatPearls [Internet]. Treasure Island (FL): StatPearls Publishing; 2020 Jan. https://www.ncbi.nlm.nih.gov/books/NBK482187/

55. Steinman H: FACTS: Food \& Allergy Consulting \& Testing Services Invited communication: Nutritional implications of food allergies. South African Journal of Clinical Nutrition. 2010, 23(1):S37-S41

56. Allen KJ, Turner PJ, Pawankar R, Taylor S, Sicherer S, Lack G, Rosario N, Ebisawa M, Wong G, and Mills ENC: Precautionary labelling of foods for allergen content: Are we ready for a global framework? World Allergy and Organ Journal. 2014, 7: 10.

57. Patel A, and Bahna SL: Hypersensitivities to sesame and other common edible seeds. Allergy. 2016, 71:14051413.

58. Adatia A, Clarke AE, Yanishevsky Y, and Ben-Shoshan M: Sesame allergy: Current perspectives. Journal of Asthma Allergy. 2017, 10:141-151.

59. Fernandez-Rivas M: Fruit and vegetable allergy. Chemical Immunology and Allergy. 2015, 101:162-170.

60. Gomez F, Aranda A, Campo P, Diaz-Perales A, BlancaLopez N, Perkins J, Garrido M, Blanca M, Mayorga C, and Torres MJ: High prevalence of lipid transfer protein sensitization in apple allergic patients with systemic symptoms. PLoS One. 2014, 9, e107304.

61. Sommer I, MacKenzie H, Venter C, and Dean T: Factors influencing food choices of food-allergic consumers: findings from focus groups. Allergy. 2012, 67:1319-1322.

62. Seth D, Poowutikul P, Pansare $M$, and Kamat D: Food Allergy: A Review. Pediatric Annals. 2020, 49(1):e50-e58. doi:10.3928/19382359-20191206-01. PMID: 31930423.

63. Leonard SA, and Nowak-Wegrzyn AH: Baked milk and egg diets for milk and egg allergy management. Immunology and Allergy Clinics of North America. 2016, 36: 147-159.

64. Leonard SA, Sampson HA, Sicherer SH, Noone S, Moshier EL, Godbold J, and Nowak-Wegrzyn A: Dietary baked egg accelerates resolution of egg allergy in children. Journal of Allergy and Clinical Immunology. 2012,130: 473-480.

65. Savage J, Sicherer S, and Wood R: The natural history of food allergy. The Journal of Allergy and Clinical Immunology: In Practice. 2016, 4: 196-203

66. D'Auria E, Abrahams M, Zuccotti GV, and Venter C: Personalized Nutrition Approach in Food Allergy: Is It Prime Time Yet? Nutrients. 2019, 11(2):359 https://doi.org/10.3390/nu11020359 